\title{
Kinetics of oxidation of toluidine blue by periodate: Catalysis by water pools of CTAB
}

\author{
K.V. Nagalakshmi ${ }^{a *}$, P. Shyamala ${ }^{b}$ and P.V. Subba Rao ${ }^{c}$
}

${ }^{a}$ Department of Chemistry, G.V.P.College of Engineering (Autonomous), Madhurawada, Visakhapatnam-530048, India ${ }^{b}$ Department of Physical chemistry, Andhra University, Visakhapatnam-530017, India ${ }^{c}$ Retired Professor, Department of Physical chemistry, Andhra University, Visakhapatnam-530017, India

\begin{tabular}{l}
\hline C H R O N I C L E \\
\hline Article history: \\
Received June 28, 2018 \\
Received in revised form \\
July 20, 2018 \\
Accepted August 20, 2018 \\
Available online \\
August 20, 2018 \\
\hline Keywords: \\
Kinetics \\
Oxidation \\
Toluidine blue \\
Periodate \\
Water pools \\
\hline
\end{tabular}

\begin{abstract}
A B S T R A C T
Kinetic study of oxidation of toluidine blue $\left(\mathrm{TB}^{+}\right)$by periodate was carried out in aqueous medium and also in the cetyl trimethyl ammonium bromide (CTAB) reverse micellar medium. In both the media reaction obeys first order kinetics with respect to each of the reactants. In the reverse micellar medium, the reaction is forty times faster compared to aqueous medium under identical experimental conditions. The pronounced acceleration is accounted for by the lower micro polarity and the concentration effect present in the bound water of reverse micelles. In $\mathrm{CTAB}$ reverse micellar medium, the pseudo first order rate constant $\left(\mathrm{k}^{\prime}\right)$ of the reaction is almost constant at all values of $W,\left\{W=\left[\mathrm{H}_{2} \mathrm{O}\right] /[\mathrm{CTAB}]\right\}$ indicating that the reaction takes place on the micellar surface and results were explained by modified Berezin pseudo phase model.
\end{abstract}

C 2018 Growing Science Ltd. All rights reserved.

\section{Introduction}

The solubilised water present in the polar cavity of reverse micelles is called water pool which has unique properties like lower dielectric constant i.e. micropolarity, higher viscosity, lower thermodynamic activity of water, higher ionic strength (in the case of reverse micelles made of ionic surfactants) and altered nucleophilicity compared to water in the conventional aqueous media ${ }^{1-5}$. These anomalous properties of the water pool are dependent on a $W$ parameter, $W=\left(\left[\mathrm{H}_{2} \mathrm{O}\right] /\right.$ [Surfactant $\left.]\right)$ and as the value of $W$ increases the properties approach that of ordinary water. These physical properties of water are known to alter rates and even mechanism of the reactions ${ }^{6-8}$. In addition to these properties, there is concentration effect as the reactants are constrained in the small fraction of the water pool which also affects rates of reactions. We have earlier reported kinetics of dissociation of $\left[\mathrm{Fe}(\mathrm{tptz})_{2}\right]^{2+}$ in the presence of CTAB reverse micelles and have found that low dielectric constant of the water pool facilitates the formation of ion pair between complex and bromide ion of $\mathrm{CTAB}^{9}$. In another reaction, kinetics of oxidation of iodide by Vanadium (V) in CTAB reverse micelles, we found that concentration effect present in the water pool predominates over ionic strength and dielectric constant. ${ }^{10}$

* Corresponding author. Tel.: +891-9000900913 
Toluidine blue (3-amino-7-dimethyl-amino-2-methyl phenazathinium chloride) a phenothiazine dye, is generally used as biological sensitizer, polymerization inhibitor and complexing agent. Since the toluidine blue dye has both biological and industrial applications, micellar catalysed redox reactions of toluidine blue is therefore important and hence we have selected the oxidation of toluidine blue for studying the effect of CTAB/Hexane/Chloroform reverse micelles.

\section{Results and Discussion}

The kinetics of the reaction has been investigated in the aqueous medium and in CTAB reverse micelles under pseudo first order conditions, $\left\{\left[\mathrm{IO}_{4}^{-}\right]>>\left[\mathrm{TB}^{+}\right]\right\}$varying the concentration of periodate in the range $0.6 \times 10^{-4}$ to $60.0 \times 10^{-4} \mathrm{~mol} \mathrm{dm}^{-3}$ and keeping the concentration of $\mathrm{TB}^{+}$at $1.2 \times 10^{-5} \mathrm{~mol} \mathrm{dm}^{-}$ ${ }^{3}$ thus isolating $\mathrm{TB}^{+}$.

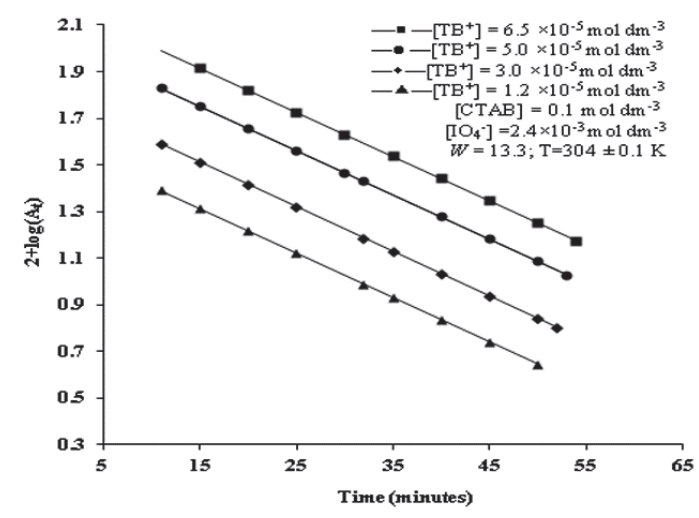

Fig. 1. Plots of $\log \left(A_{t}\right)$ versus time

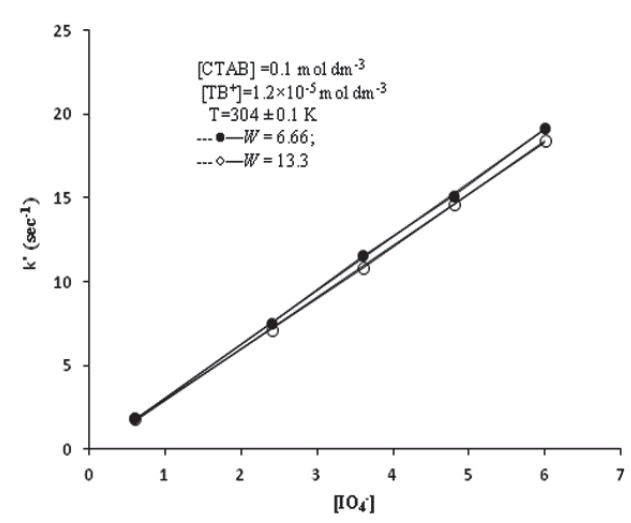

Fig. 2. Plots of $\mathrm{k}^{\prime}$ versus $\left[\mathrm{IO}_{4}^{-}\right]$

In CTAB reverse micellar medium, reaction obeys first order kinetics with respect to $\left[\mathrm{TB}^{+}\right]$as shown by linear plots between log (absorbance) versus time. (Fig.1). A plot of pseudo first order rate constant, $\mathrm{k}^{\prime}$ versus $\left[\mathrm{IO}_{4}^{-}\right]$was found to be linear passing through origin indicating first order kinetics with respect to $\mathrm{IO}_{4}^{-}$(Fig.2). The reaction has also been carried out in aqueous medium under identical conditions. Similar kinetic features were observed in aqueous medium also and are given in Table $\mathbf{1 .}$

Table 1. Pseudo first order rate constants in aqueous medium at $\mathrm{T}=304 \pm 0.1$

\begin{tabular}{cccc}
\hline $\begin{array}{c}{\left[\mathrm{TB}^{+} \times 10^{5}\right.} \\
\left(\mathrm{mol} \mathrm{dm}^{-3}\right)\end{array}$ & $\begin{array}{c}{\left[\mathrm{IO}_{4}^{-}\right] \times 10^{3}} \\
\left(\mathrm{~mol} \mathrm{dm}^{-3}\right)\end{array}$ & $\begin{array}{c}\mu \\
\mathrm{k}^{\prime} \times 10^{5} \\
\left(\mathrm{sec}^{-1}\right)\end{array}$ & 6.61 \\
\hline 1.2 & 2.4 & 1.0 & 6.62 \\
2.5 & 2.4 & 1.0 & 6.61 \\
4.0 & 2.4 & 1.0 & 6.61 \\
6.5 & 2.4 & 1.0 & 3.38 \\
1.2 & 1.2 & 1.0 & 6.61 \\
1.2 & 2.4 & 1.0 & 16.5 \\
1.2 & 6.0 & 1.0 & 34.2 \\
1.2 & 12 & 1.0 & 66.1 \\
1.2 & 24 & 1.0 & 12.5 \\
1.2 & 2.4 & 0.5 & 6.61 \\
1.2 & 2.4 & 1.0 & 3.04 \\
1.2 & 2.4 & 2.77 & 2.95 \\
\end{tabular}

To compare the rate constants of the reaction in the presence of reverse micelles and in aqueous medium, kinetic runs were carried out keeping the concentrations of reactants and ionic strengths same in the both the media. The calculation of ionic strength $(\mu)$ in the water pool (i.e. by considering the 
concentration of bromide ion of CTAB) has been carried out using the method adopted by Munoz et al ${ }^{11}$. The data are presented in the Table 2.

Table 2. Comparison of rate constants in the aqueous medium and in the presence of $0.1 \mathrm{~mol} \mathrm{dm}^{-3} \mathrm{CTAB}$ at same ionic strength $(\mu)$

\begin{tabular}{ccc}
{$\left[\mathrm{TB}^{+}\right]=1.2 \times 10^{-5} \mathrm{~mol} \mathrm{dm}^{-3} ;\left[\mathrm{IO}_{4}^{-}\right]=2.4 \times 10^{-3} \mathrm{~mol} \mathrm{dm}^{-3} ; \mathrm{T}=304 \pm 0.1 \mathrm{~K}$} & \\
\hline $\begin{array}{c}{\left[\mathrm{Br}^{-}\right]_{\mathrm{e}}} \\
\left(\mathrm{mol} \mathrm{dm}^{-3}\right)\end{array}$ & $\begin{array}{c}\mathrm{k}_{\text {aq.med }}^{\prime} \times 10^{5} \\
\left(\mathrm{sec}^{-1}\right)\end{array}$ & $\begin{array}{c}\mathrm{k}_{\text {rev mic }}^{\prime} \times 10^{4} \\
\left(\mathrm{sec}^{-1}\right)\end{array}$ \\
\hline 2.77 & 3.04 & 7.51 \\
3.33 & 2.95 & 7.48 \\
4.16 & 1.89 & 7.45 \\
\hline
\end{tabular}

It can be seen that at the same ionic strength and reactant concentrations, the pseudo first order rate constant is about forty times more in the presence of reverse micelle compared to the aqueous medium at $\mu=4.16 \mathrm{~mol} \mathrm{dm}^{-3}$. The same rate constant is around twenty times in the reverse micelle at an ionic strength of $2.77 \mathrm{~mol} \mathrm{dm}^{-3}$. The large acceleration in the reverse micelle is due to two reasons; one is concentration effect as the reactants are constrained in the small fraction of the water pool and other is low dielectric constant of the water pool which facilitates the reaction between the two oppositely charged ions.

\section{Effect of $W$ and $[C T A B]$}

The reaction has been carried out at different $W$ values keeping the concentration of CTAB at 0.1 mol dm${ }^{-3}$. The study has been repeated at $0.2 \mathrm{~mol} \mathrm{dm}^{-3}$ and $0.3 \mathrm{~mol} \mathrm{dm}^{-3} \mathrm{CTAB}$ concentrations. The results are given in the Table 3.

Table 3. Effect of variation of $W$ and [CTAB]

$\left[\mathrm{TB}^{+}\right]=1.2 \times 10^{-5} \mathrm{~mol} \mathrm{dm}^{-3} ;\left[\mathrm{IO}_{4}^{-}\right]=2.4 \times 10^{-3} ; \mathrm{T}=304 \pm 0.1 \mathrm{~K}$

\begin{tabular}{ccccc}
\hline $\begin{array}{c}{[\mathrm{CTAB}]^{-3}} \\
\left(\mathrm{~mol} \mathrm{dm}^{-3}\right)\end{array}$ & {$\left[\mathrm{Br}^{-}\right]_{\mathrm{e}}$} & $\begin{array}{c}10^{3} \times f \\
(\text { volume fraction })\end{array}$ & $W$ & $\begin{array}{c}\mathrm{k}^{\prime} \times 10^{4} \\
\left(\mathrm{sec}^{-1}\right)\end{array}$ \\
\hline 0.1 & 16.6 & 6.00 & 3.33 & 7.12 \\
& 12.5 & 8.00 & 4.44 & 7.26 \\
& 8.33 & 12.0 & 6.66 & 7.14 \\
& 6.25 & 16.0 & 8.88 & 7.26 \\
& 4.16 & 24.0 & 13.3 & 7.48 \\
& 3.33 & 30.0 & 16.6 & 7.51 \\
\hline 0.2 & 3.77 & 12.0 & 20.0 & 4.21 \\
& 16.6 & 16.0 & 3.33 & 4.35 \\
& 12.5 & 24.0 & 4.44 & 4.40 \\
& 8.33 & 32.0 & 6.66 & 4.85 \\
& 6.25 & 48.0 & 8.88 & 4.97 \\
& 4.16 & 60.0 & 13.3 & 5.01 \\
\hline 0.3 & 3.33 & 12.0 & 20.6 & 3.15 \\
& 2.77 & 18.0 & 3.33 & 3.26 \\
& 16.6 & 24.0 & 4.44 & 3.29 \\
& 12.5 & 36.0 & 6.66 & 3.95 \\
& 8.33 & 48.0 & 8.88 & 3.56 \\
& 6.25 & 72.0 & 13.3 & 3.71 \\
& 4.16 & 90.0 & 16.6 & 3.78 \\
\hline
\end{tabular}


The pseudo first order rate constant $\mathrm{k}^{\prime}$ is almost constant with increase in $W$ at constant [CTAB]. This constancy indicates that the reaction takes place on the micellar surface. When reaction takes place in water pool of reverse micelles, the rate constant would change with $W$. Periodate is a hydrophilic species carrying negative charge, insoluble in hexane and chloroform and can be expected to be found between the aqueous water pool and the interface. The binding constant of periodate from spectrophotometric studies was found to be around $20 \mathrm{~mol}^{-1} \mathrm{dm}^{3}$. Toluidine blue can be incorporated into the cationic micelle by hydrophobic attractions. These hydrophobic attractions are sufficiently strong to overcome the electrostatic repulsions between the dye molecules and micelles of similar charge. This is indicated by the high binding constant, $1.5 \times 10^{2} \mathrm{~mol}^{-1} \mathrm{dm}^{3}$ obtained for $\mathrm{TB}^{+}$in the presence of CTAB reverse micelles at $W=3.33$ (Table 4).

$\underline{\text { Table 4. Binding constants in CTAB reverse micellar medium }}$

\begin{tabular}{cccc}
\hline \multicolumn{2}{c}{ From spectrophotometric method } & & $\begin{array}{c}\text { From kinetics } \\
\text { Toluidine blue vs } \\
\text { periodate }) \\
\left(\mathrm{mol}^{-1} \mathrm{dm}^{3}\right)\end{array}$ \\
\hline 3.33 & $\begin{array}{c}\text { Binding constant of } \\
\text { Toluidine blue }\left(\mathrm{mol}^{-1} \mathrm{dm}^{3}\right)\end{array}$ & $\begin{array}{c}\text { Binding constant of } \\
\text { periodate }) \\
\left(\mathrm{mol}^{-1} \mathrm{dm}^{3}\right)\end{array}$ & $\begin{array}{c}23.9 \\
6.66\end{array}$ \\
16.6 & $1.53 \times 10^{2}$ & 22.5 & 19.3 \\
\hline
\end{tabular}

There entire reaction take place at interface. To explain the experimental results obtained in the kinetic study of the reaction between $\mathrm{TB}^{+}$and $\mathrm{IO}_{4}^{-}$, the reaction scheme1 has been considered,

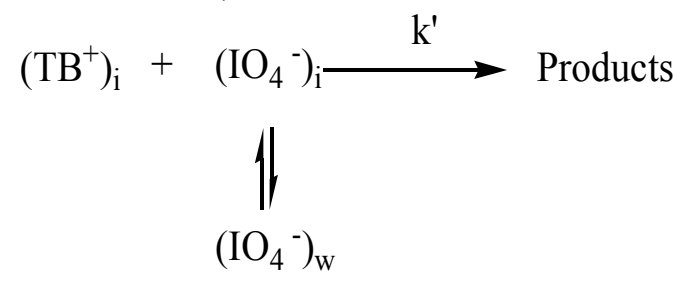

\section{Scheme 1}

where ' $i$ ' represents micellar interface and ' $w$ ' represents water pool of reverse micelles. The following mass balance equations developed by Berezin ${ }^{12,13}$ can be used to calculate the concentration of $\mathrm{TB}^{+}$ and $\mathrm{IO}_{4}^{-}$in the micellar phase,

$\mathrm{p}_{\mathrm{TB}^{+}}=\frac{\left[\mathrm{TB}^{+}\right]_{\mathrm{M}}}{\left[\mathrm{TB}^{+}\right]_{\mathrm{W}}}$.

where $\mathrm{p}_{\mathrm{TB}^{+}}$is the distribution coefficient of $\mathrm{TB}^{+}$.

$\left[\mathrm{TB}^{+}\right]_{\mathrm{W}}=\frac{\left[\mathrm{TB}^{+}\right]_{\mathrm{M}}}{\mathrm{p}_{\mathrm{TB}^{+}}}$.

If $\left[\mathrm{TB}^{+}\right]_{0}$ is the total concentration of $\mathrm{TB}^{+}$then, $\left[\mathrm{TB}^{+}\right]_{\mathrm{o}}=\left[\mathrm{TB}^{+}\right]_{\mathrm{W}}+\left[\mathrm{TB}^{+}\right]_{\mathrm{M}}$ and

$\left[\mathrm{TB}^{+}\right]_{\mathrm{o}}=\left[\mathrm{TB}^{+}\right]_{\mathrm{W}}(1-\mathrm{CV})+\left[\mathrm{TB}^{+}\right]_{\mathrm{M}} \mathrm{CV}$,

where $\mathrm{C}$ is the concentration of the micelle and $\mathrm{V}$ is the molar volume.

From Eq. (2) and Eq. (3)

$$
\left[\mathrm{TB}^{+}\right]_{\mathrm{o}}=\frac{\left[\mathrm{TB}^{+}\right]_{\mathrm{M}}(1-\mathrm{CV})}{\mathrm{p}_{\mathrm{TB}^{+}}}+\left[\mathrm{TB}^{+}\right]_{\mathrm{M}} \mathrm{CV}
$$

Neglecting CV in comparison to 1 ,

$$
\left[\mathrm{TB}^{+}\right]_{\mathrm{o}}=\left[\mathrm{TB}^{+}\right]_{\mathrm{M}}\left(\mathrm{CV}+\frac{1}{\mathrm{p}_{\mathrm{TB}^{+}}}\right) ;\left[\mathrm{TB}^{+}\right]_{\mathrm{M}}=\frac{\left[\mathrm{TB}^{+}\right]_{\mathrm{o}} \mathrm{p}_{\mathrm{TB}^{+}}}{\mathrm{p}_{\mathrm{TB}^{+}} \mathrm{CV}+1} \text {. }
$$


Hence, $\left[\mathrm{TB}^{+}\right]_{\mathrm{M}}=\frac{\left[\mathrm{TB}^{+}\right]_{\mathrm{o}} \mathrm{p}_{\mathrm{TB}^{+}}}{\left(\mathrm{K}_{\mathrm{TB}^{+}} \mathrm{C}+1\right)}$

$\mathrm{K}_{\mathrm{TB}^{+}}=\mathrm{p}_{\mathrm{TB}^{+}} \mathrm{V}$, Since $\mathrm{K}_{\mathrm{TB}^{+}}=1.53 \times 10^{2} ; \quad 1+\mathrm{K}_{\mathrm{TB}^{+}} \mathrm{C} \sim \mathrm{K}_{\mathrm{TB}^{+}} \mathrm{C}$.

Therefore, $\left[\mathrm{TB}^{+}\right]_{\mathrm{M}}=\frac{\left[\mathrm{TB}^{+}\right]_{\mathrm{o}} \mathrm{p}_{\mathrm{TB}^{+}}}{\mathrm{K}_{\mathrm{TB}^{+}} \mathrm{C}}$.

Similarly, $\left[\mathrm{IO}_{4}^{-}\right]_{\mathrm{M}}=\frac{\left[\mathrm{IO}_{4}^{-}\right]_{0} \mathrm{p}_{\mathrm{IO}_{4}^{-}}}{1+\mathrm{K}_{\mathrm{IO}_{4}^{-}} \mathrm{C}}$.

According to Berezin model,

rate $=\mathrm{k}_{\mathrm{M}}\left[\mathrm{TB}^{+}\right]_{\mathrm{M}}\left[\mathrm{IO}_{4}^{-}\right]_{\mathrm{M}} \mathrm{CV}+\mathrm{k}_{\mathrm{W}}\left[\mathrm{TB}^{+}\right]_{\mathrm{W}}\left[\mathrm{IO}_{4}^{-}\right]_{\mathrm{W}}(1-\mathrm{CV})$

Since the reaction is much faster in the presence of CTAB reverse micelles, $\mathrm{k}_{\mathrm{W}}$ can be neglected. rate $=\mathrm{k}_{\mathrm{M}}\left[\mathrm{TB}^{+}\right]_{\mathrm{M}}\left[\mathrm{IO}_{4}^{-}\right]_{\mathrm{M}} \mathrm{CV}$

From Eq. (6) and Eq. (7),

$$
\begin{aligned}
& \text { rate }=\mathrm{k}_{\mathrm{M}} \frac{\left[\mathrm{TB}^{+}\right]_{\mathrm{o}} \mathrm{p}_{\mathrm{TB}^{+}}}{\mathrm{K}_{\mathrm{TB}^{+}} \mathrm{C}} \frac{\left[\mathrm{IO}_{4}^{-}\right]_{\mathrm{o}} \mathrm{p}_{\mathrm{IO}_{4}^{-}} \mathrm{CV}}{\left(1+\mathrm{K}_{\mathrm{IO}_{4}^{-}} \mathrm{C}\right)} \text {, } \\
& \mathrm{k}^{\prime}=\frac{\mathrm{k}_{\mathrm{M}} \mathrm{p}_{\mathrm{TB}^{+}} \mathrm{p}_{\mathrm{IO}_{4}^{-}} \mathrm{CV}}{\mathrm{K}_{\mathrm{TB}^{+}} \mathrm{C}\left(1+\mathrm{K}_{\mathrm{IO}_{4}^{-}} \mathrm{C}\right)} \text {, } \\
& \mathrm{k}^{\prime}=\frac{\mathrm{k}_{\mathrm{M} \mathrm{p}_{\mathrm{IO}_{4}^{-}}}}{\left(1+\mathrm{K}_{\mathrm{IO}_{4}^{-}} \mathrm{C}\right)} \text {, } \\
& \frac{1}{\mathrm{k}^{\prime}}=\frac{1}{\mathrm{k}_{\mathrm{M} \mathrm{p}_{4}^{-}}}+\frac{\mathrm{K}_{\mathrm{IO}_{4}^{-}} \mathrm{C}}{\mathrm{k}_{\mathrm{M}} \mathrm{p}_{\mathrm{IO}_{4}^{-}}} \text {. }
\end{aligned}
$$

According to Eq. (10), the plot of $1 / \mathrm{k}^{\prime}$ versus concentration of CTAB (C) was found to be a straight line (Fig.3) and from the slope and intercept the binding constant of periodate was determined at different $W$ values. The binding constants obtained from the plots are in good agreement with the values measured from spectrophotometry (Table 4).

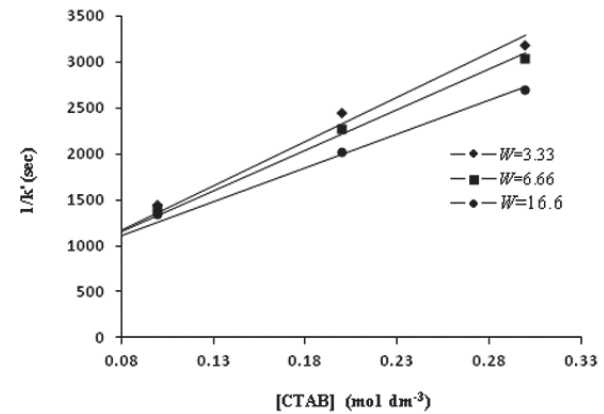

Fig. 3. Plots of $1 / k^{\prime}$ versus $[C T A B]$

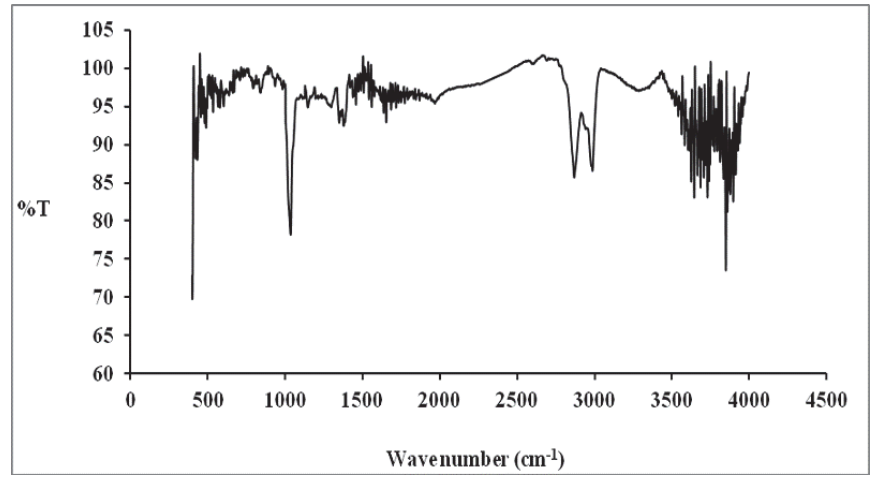

Fig. 4. IR spectrum of the product 


\section{Conclusions}

When investigating the kinetics of oxidation of Toluidine blue by Periodate in $\mathrm{CTAB} /$ Hexane/Chloroform reverse micelles, it was found that:

1. The reaction has been found to be accelerated around forty times in the presence of CTAB reverse micelles. Significant increase of rate in the CTAB reverse micellar medium is due low micro polarity of bound water of reverse micelles which facilitates the reaction between two oppositely charged ions.

2. The pseudo first order rate constant $\left(\mathrm{k}^{\prime}\right)$ of the reaction is almost constant at all values of $W$, indicating that the reaction entirely takes place on the micellar interface. When reaction takes place in water pool of reverse micelles, the rate constant would change with $W$.

3. The plots of pseudo first order rate constant $\left(\mathrm{k}^{\prime}\right)$ versus concentration of CTAB were linear and binding constants obtained from these plots are in good agreement with the values measured from spectrophotometry. The linearity shows the validity of Berezin pseudo phase model for this reaction in reverse micellar medium.

\section{Acknowledgements}

We (KVNL and PS) thank UGC, India under the minor research project MRP-4552(14) (SERO/UGC) and DST, India under the project SERB/F/5725/2013-14 respectively for financial support.

\section{Experimental}

\subsection{Materials}

Stock solutions of toluidine blue (Sigma, India) and sodium periodate (Merck, India) were prepared in triple distilled water. Chloroform and hexane were double distilled before use. CTAB (Cetyl tri methyl ammonium bromide) purchased from Sigma was used without further purification. Reverse micellar solutions of CTAB $\left(0.1 \mathrm{~mol} \mathrm{dm}^{-3}, 0.2 \mathrm{~mol} \mathrm{dm}^{-3}\right.$ and $\left.0.3 \mathrm{~mol} \mathrm{dm}^{-3}\right)$ were prepared by dissolving requisite amounts of $\mathrm{CTAB}$ in chloroform-hexane $(3: 2 \mathrm{v} / \mathrm{v})$ mixtures.

\subsection{Preparation of reverse micellar medium and initiation of the reaction}

$0.04 \mathrm{ml}$ of periodate solution $\left(0.6 \mathrm{~mol} \mathrm{dm}^{-3}\right)$ was injected into $10 \mathrm{ml}$ of $0.1 \mathrm{~mol} \mathrm{dm}^{-3} \mathrm{CTAB}$ solution using a micro pipette. $0.02 \mathrm{ml}$ of toluidine blue solution $\left(0.006 \mathrm{~mol} \mathrm{dm}^{-3}\right)$ was then added to begin the reaction. The reaction mixtures were shaken vigorously to obtain a transparent and homogenous solution that can be regarded as a reverse micellar system. The molar ratio of [Water] to [CTAB] i.e. $W$ was varied in the range 3.33 to 20.0 .

\subsection{Determination of Binding Constants}

The binding constants of toluidine blue and periodate were determined in $\mathrm{CTAB} /$ Hexane/Chloroform reverse micelles at $W=3.33, W=6.66$ and $W=16.6$. The absorbance of toluidine blue (at $\lambda=626 \mathrm{~nm}$ ) and periodate (at $\lambda=260 \mathrm{~nm}$ ) has been recorded for different concentrations of CTAB. The binding constant $(\mathrm{K})$ has been determined ${ }^{14,15}$ from the plot of $\frac{1}{\left(\mathrm{~A}_{\mathrm{M}}-\mathrm{A}_{\mathrm{W}}^{0}\right)}$ versus $1 / \mathrm{C}$ using the Eq. (11),

$$
\frac{1}{\left(\mathrm{~A}_{\mathrm{M}}-\mathrm{A}_{\mathrm{W}}^{\mathrm{o}}\right)}=\frac{1}{\left(\mathrm{~A}_{\mathrm{M}^{-}}^{\mathrm{o}} \mathrm{A}_{\mathrm{W}}^{\mathrm{o}}\right)}+\frac{1}{\left(\mathrm{~A}_{\mathrm{M}^{-}}^{\mathrm{o}} \mathrm{A}_{\mathrm{W}}^{\mathrm{o}}\right) \mathrm{KC}},
$$


where, $A_{M}$ is the absorbance in reverse micelles; $A_{W}^{o}$, the absorbance in water, $A_{M}^{o}$ is the limiting absorbance in reverse micelles and $\mathrm{C}$, the concentration of reverse micellar solution.

\subsection{Kinetic measurement}

The kinetics of the reaction was monitored by measuring the decrease in absorbance of toluidine blue at a wave length of $626 \mathrm{~nm}\left(\varepsilon_{626}=29,800 \mathrm{~mol}^{-1} \mathrm{~cm}^{-1}\right)$ using a SHIMADZU double beam spectrophotometer. The reaction was carried out under pseudo first order condition, $\left[\mathrm{IO}_{4}^{-}\right]>>\left[\mathrm{TB}^{+}\right]$at $304 \pm 0.1 \mathrm{~K}$. The pseudo first order rate constants were obtained from slopes of log (absorbance, $A_{t}$ ) versus time. The experimental data are the averages from duplicate runs with reproducibility less than $\pm 4 \%$.

\subsection{Product analysis}

$\mathrm{TB}^{+}\left(1.2 \times 10^{-5} \mathrm{~mol} \mathrm{dm}{ }^{-3}\right)$ and periodate $\left(2.4 \times 10^{-3} \mathrm{~mol} \mathrm{dm}^{-3}\right)$ were mixed to make $500 \mathrm{ml}$ solution. After 24 hours, the organic components were extracted into diethyl ether and subjected for Infrared analysis. The Infrared spectrum of the product showed a sharp band at $1005-1070 \mathrm{~cm}^{-1}$, suggesting the formation of sulfoxide. No intense peaks indicative of sulfones in the region of $1300-1135 \mathrm{~cm}^{-1}$ were observed which excludes the formation of sulfone. The strong peaks in the ranges of $3000-3300 \mathrm{~cm}^{-1}$ and 2700-3000 $\mathrm{cm}^{-1}$ indicated the presence of intact primary and secondary amino groups on the aromatic heterocyclic ring. (Fig.4). From stoichiometry and product analysis the overall reaction is given in scheme 2.

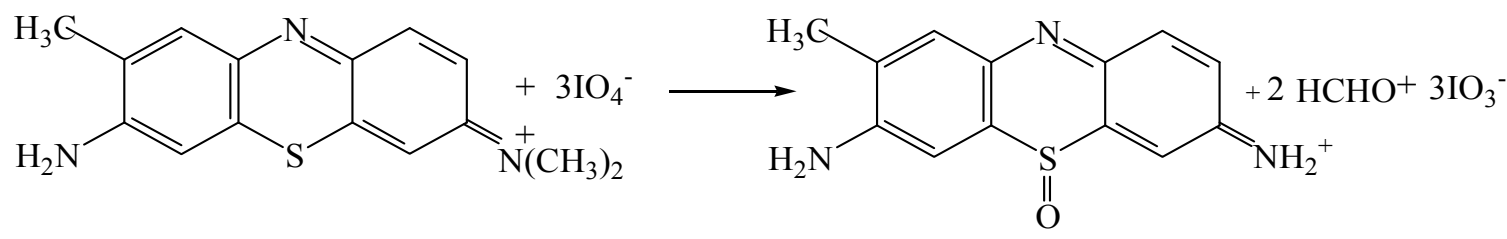

Scheme 2

\section{References}

1. Menger F. M., Donohue J. A., and Williams R. F. (1973) Catalysis in water pools. J. Am. Chem. Soc., 95(1) 286-288.

2. Goto A., and Kishimoto H. (1989) The Addition of the Cyanide Ion to the $N$-Methyl-3carbamoylpyridinium Ion in Reversed Micelles. Bull. Chem. Soc. Jpn, 62 2854-2861.

3. Sunamoto J., Hamada T. (1978) Solvochromism and Thermochromism of Cobalt(II) Complexes Solubilized in Reversed Micelles. Bull. Chem. Soc. Jpn, 51, 3130-3135.

4. Bridge N. J., and Fletcher P. D. I. (1983) Time-resolved studies of fluorescence quenching in a water-in-oil microemulsion. J. Chem. Soc. Faraday Trans., 79(9) 2161-2169.

6. Harasit K. M., Majumdar T., and Ambikesh M. (2011) Kinetics of basic hydrolysis of tris(1,10-phenanthroline)iron(II) in macromolecular assemblies of CTAB Int. J .Chem. Kinet, 43(10) 579-589.

7. Johnson M.D., Lorenz B.B., Wilkins P.C., Lemons B.G., Baruah B., Lamborn N., Stahla M., Chatterjee P.B., Richens D.T., and Crans D.C. (2012) Switching Off Electron Transfer Reactions in Confined Media: Reduction of $\left[\mathrm{Co}(\text { dipic })_{2}\right]^{-}$and $[\mathrm{Co}(\text { edta })]^{-}$by Hexacyanoferrate(II). Inorg. Chem., 51(5) 2757-2765.

8. Jamil K. J. S. (2006) Kinetics of the Oxidation of Phenylhydrazine by $\left[\mathrm{Fe}(\mathrm{CN})_{6}\right]^{3-}$ in Waterin-Oil Microemulsion. J. Dispersion. Sci. Technol, 27(6) 795-798. 
9. Nagalakshmi K.V., padma M., Srikanth V., Shyamala P., and Subba Rao P.V. (2013) Catalytic effect of CTAB reverse micelles on the kinetics of dissociation of bis $(2,4,6-$ tripyridyl-s-triazine) iron(II). Transition Met Chem, 38 523-527.

10. Shyamala P., and Subba Rao P.V. (2010) Kinetics of Oxidation of Iodide by Vanadium (V):Catalysis by the Water Pools of CTAB Reverse Micelles. Kinet. Catal, 51(2) 207-210.

11. Munoz E., Gomez - Herrera C., Garciani M., Moya M L., and Sanchez F. (1991) Kinetics of the oxidation of iodide by persulphate in AOT-oil-water microemulsions .J Chem Soc, Faraday Trans, 87(1) 129-132.

12. Silber J. J., Biasutti A., Abunin E. (1999) Interactions of small molecules with reverse micelles. Adv in Colloid and Interface Sci., 82(1) 189-252.

13. Fletcher P.D.I., Robinson B.H. (1984) Effect of organized surfactant systems on the kinetics of metal-ligand complex formation and dissociation. J. Chem. Soc. Faraday Trans., 80(1) 2417-2437.

14. Sepulveda L. (1974) Absorbances of solutions of cationic micelles and organic anions. $J$ Colloid Interface Sci, 46(3) 372-379.

15. Srikanth V., Shyamala P., Satyanarayana A., and Subba Rao P.V. (2012) Alkaline hydrolysis of isatin in the presence of mixed CTAB and Triton X-100 micellar systems: Micellisation and kinetic investigations. Indian J. of Chem., 51(A) 1701-1705.

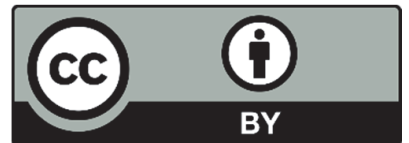

(C) 2018 by the authors; licensee Growing Science, Canada. This is an open access article distributed under the terms and conditions of the Creative Commons Attribution (CC-BY) license (http://creativecommons.org/licenses/by/4.0/). 